\title{
Migrant Housing in Urban China: Based on Residential Segregation and Social Exclusion Theory
}

\author{
Murong Guo, Zicheng Wang \\ School of Public Management, Jinan University, Guangzhou, China \\ Email: guomurong1@126.com
}

Received 24 May 2015; accepted 4 July 2015; published 7 July 2015

Copyright (C) 2015 by authors and Scientific Research Publishing Inc.

This work is licensed under the Creative Commons Attribution International License (CC BY).

http://creativecommons.org/licenses/by/4.0/

(c) (i) Open Access

\begin{abstract}
China's recent waves of internal migration, primarily rural to urban reflect a rapidly urbanizing society. However, how to settle down the migrants to promote the process of urbanization, housing problem has become a central topic among scholars. This article mainly reviews the present situation of migrant housing in urban China from four aspects, such as housing choice, spatial distribution of residence, housing condition and housing satisfactory. Based on residential segregation and social exclusion theory, the research finds that the country's unique institutional factors, particularly the existing household registration system, together with the individual characteristics, contribute to the overall poor conditions of migrant housing. Thus, several effective measures should be implemented to improve the living standard of migrant housing.
\end{abstract}

\section{Keywords}

Migrant Housing, Residential Segregation, The Household Registration System

\section{Introduction}

Farmers, as the surplus labor in rural area, have been migrating to cities since the reforming and opening-up, highly promoted the process of urbanization. As shown in the survey data of migrant workers in 2014, there are approximately 274 million migrant workers in total on a national scale, among which, the number of migrant workers leaving home is 168 million, accounting for a percentage of $61.4 \%$ [1]. The $18^{\text {th }}$ Communist Party Congress suggests accelerating the urbanization of migrant workers. However, the housing problem is the foundation and the critical factor for the urbanization of migrant workers. To settle down the migrant workers' housing problem has thus become a central topic among scholars.

This article, consisting of five main sections, introduces relevant theory, reviews the existing situation of mi-

How to cite this paper: Guo, M.R. and Wang, Z.C. (2015) Migrant Housing in Urban China: Based on Residential Segregation and Social Exclusion Theory. Open Journal of Business and Management, 3, 281-286.

http://dx.doi.org/10.4236/ojbm.2015.33028 
grant housing in urban China from four aspects such as the housing choice, spatial distribution of residence, housing condition and housing satisfactory, analyzes the influencing factors leading to the constrains, proposes the measures and suggestions to improve the living standard, and makes a conclusion.

\section{Theoretical Basis}

\subsection{Residential Segregation Theory}

Scholars mainly focus on some special groups, like migrants, minorities and races. They propose a theory, Residential Segregation, which a preference of living in compact community, diversity of financial capacity, and the deviation of policy lead to the residential segregation. As indicated by Schelling (1971), residential segregation is a self isolation resulted from the preference of living in compact community caused by cultural identity. In a multiracial society, people's decisions are affected by their personal preferences of cultural homogeneity [2], in other words, people tend to affiliate with their own race. However, given the residential segregation comparison against the black people, Spanish, Asians, Denton (1988) found out that the segregation problem of wealthy black people is more serious than the poorest Hispanic families [3]. It seems that personal preference is not the exclusive factor of residential segregation. Most of them are forced to choose residential segregation, especially the black people. Meanwhile, Preston et al. (2007) indicates a phenomenon that housing decision of individual is affected by their purchasing power. Poor immigrants choose the community with relatively low housing rental, while rich immigrants choose the residence with better living condition [4], leading to a residential segregation based on the diversity of financial capacity. Except the cultural and economic factors, Hanlon (2011) puts forward an idea that the deviation of policy further accelerates residential segregation [5]. In 1950s, the U.S. Housing and Urban Development (HUD) had kept cutting down the public housing fund, caused a decline of the living space and living comfort. The white men therefore have fled away from the area. The public housing area gradually became the gathering area of black people, which further accelerate the racial residential segregation [6].

\subsection{Social Exclusion Theory}

Scholars mainly focus on the social exclusion in trading and distribution, e.g. mortgage loan and subprime mortgages discrimination [7], ethnic insulation and apartheid barrier [8] [9], when handling with the issue of housing guarantee. The existence of social exclusion leads the immigrants have a limited possibility to own private house or get public rental house than the natives [10]. By taking the benefit of the National Longitudinal Survey of Youth 1979 (NLSY79) data, Chatterjee (2011) found that immigrants who make the decision to own homes are more likely to have greater housing equity than native-born residents. Because the immigrants have insufficient knowledge of the U.S. banking system and the existence of consumption credit restriction, they have to pay a higher down-payment. Thus, the migrants have a more powerful control on housing and it leads to a more guaranteed housing right [11]. And it also proves that the social exclusion about the immigrants in housing market does really exist.

\section{The Present Situations of Migrant Housing in Urban China}

\subsection{Housing Choices}

Rental housing, which is private housing in areas that used to be or still are agricultural within the metropolis, is a particularly popular option for migrants settling in suburban areas in both cities in urban China, with a variety of housing types being involved. The China national survey of 31 provinces on migrant workers in 2014 shows that about $36.9 \%$ of migrants live in rental housing, while $28.3 \%$ of migrants live in collective dormitories provided by enterprise [1], especially the labor intensive firms. Other choices of housing, including self-built sheds and temporary housing on construction site, only accommodate a small of number of migrants. Above of the housing choices, tenants just have use right. The proportion of migrants who have purchased ownership right to their housing in urban or small town is minimal among migrants, about 1\% [1]. Income level, together with government restriction, is likely the key factors for migrants to access to housing.

\subsection{Spatial Distribution of Residence}

The residential choice of migrants in space distribution takes place in two types: through living in a compact 
community and through living in small and dispersed groups.

There are three mechanisms to contribute the former type. Firstly, based on the kinship and friendship ties, a bulk of migrants who come from the same origin areas gather in a certain urban region through joint introduction and then form the China's unique collective inhabitation areas, such as Zhejiang village, Xinjiang village of Bejing and Han Cunhe. A survey shows that in a restaurant operated by the Uygur owner, about $70 \%$ of employees are boss's congenial fellow or relatives, and most of them live in the Xinjiang village of Bejing [12]. Secondly, the rapid urbanization producing a lot of extraneous people, with the increasing of the population density in central city, the house rent in there becomes more and more expensive. To cut down the living expenses, more and more migrants constantly move to the edge of the city, finally forming the China's unique city village which refers to village within and on the fringe urban area in China where would provide cheap accommodation for the rural-urban migrants. Thirdly, driven by capital, a host of collective dormitories are built in the urban industrial or economic development zone by such companies operated under the dormitory labor system, a specific Chinese labor system combining with work and residence. Thus, these three mechanisms lead to the collective residential choice of migrants.

However, the latter refers to the scattered living-migrants (e.g., individual industrial and commercial households, casual workers and family nanny) live scattered in widely urban community mixed with local residents. This is largely determined by the nature of their work.

\subsection{Housing Conditions}

Migrant housing in urban China is at best mediocre, and many migrants endured harsh housing conditions in comparison with the local residents. The following analysis is mainly focusing on the housing conditions of the private housing built in suburban areas and the collective dormitory provided by the labor intensive companies.

The poor living conditions of the private housing for migrants renting is mainly reflected in four aspects. Firstly, per capita living space is low. A housing survey in 2008 and 2009 in Zhengzhou shows that the average per capita living space of two-thirds of migrants in survey is below 10 square meters, of which $18 \%$ is still below 3 square meters, of local residents is 26.08 square meters [13]. Secondly, building density is crowded. Such informal housings as self-help and self-constructed housings are built everywhere in suburban areas by famers or former famers on land allotted by their production brigades. The distance between two buildings is especially short. Because of the poor lighting in the room, tenants either day or night at home must to turn on the lights. Thirdly, the matching basic public facilities and services is badly off-lack of fire fighting equipments, slowly perishing circuit, and short of ventilation system. Besides, the residential humanities environment is poor for migrants because they are often discriminated by locals.

As the rented private housing, the conditions of collective dormitory are also unsatisfactory-short of basic living facilities, low per capita housing space and lack of autonomy and privacy. It isn't fuss that a floor or even the whole building shared a bathroom and toilet in the staff dormitory. In the dormitory, there is no room for personal privacy because of living space is collective sharing. More seriously, combining work and residence under the dormitory labor system, company executives control almost all daily reproduction of labor. In other words, employees living in a dorm means that management rights is easy to infiltrate into their daily life. The illegal behavior of arbitrary extension of working day and labor time are more prone to take place in comprised with the non-dormitory labor system.

In a word, the living conditions are worsened either in the interrelated nature of housing availability, affordability or in qualitative aspects of the residential environment.

\subsection{Housing Satisfaction}

Small per capita living space, less well-built dwelling, together with the discrimination from local is the true portrayal of migrant housing conditions. Given the overall inadequate housing conditions, however, migrants express less dissatisfaction with their current housing situations. The survey in Zhengzhou reveals that about $80 \%$ of migrants feel neutral or good about their housing conditions [13]. This contradiction and paradox can be summarized as three main reasons. First of all, for the sake of uncertain income, inclining to conservative consumption, migrants have a rationale or even lower expectation on housing conditions. Unable to afford the high rents in that central location with better conditions, their housing needs and motivation is still in the level of security needs, which is easier to be met. As shown in the survey data of migrant workers in 2014, migrant work- 
ers average per capita monthly consumption expenditure is 944 yuan, yet the share of living expenses accounted for its $47.1 \%$ [1]. Secondly, a super-expected gain by freeing access to housing improves the satisfaction with their current housing conditions. At the report by National Statistics bureau reveals that migrant workers who get free accommodation from the employer or units accounted for $46.8 \%$ of the proportion of total migrant workers. Thirdly, the subjective well-being and the extra satisfaction come from the comparison with the surrounding populations. Compared with the reference group of migrant workers whose living conditions are worse, their subjective satisfaction will be higher. Obviously, the unexpectedly high housing satisfaction generates by the cautious consumption and the psychology of social comparison. If in a higher demand, the pursuit of comfort and enjoyment, a majority of exiting migrant housing can’t meet their fundamental needs.

\section{Influencing Factors: Micro and Macro Level}

There is a great deal of complex factors lead to worse overall housing conditions. The key objective of following analysis is to understand the constraints migrants faced in their housing choices within the level of micro and macro and under the theory of residential segregation and social exclusion.

\subsection{Micro Level: Individual Factors}

Chief among the microcosmic factors can be divided into three aspects: personal and family characteristics, employment and financial capacity. The combined of individual factors seems to have a particularly strong impact on migrants access to housing in urban.

The most important one are financial capacity which linkage with their income. Income could be expected to be influence even with restricted access to urban housing for migrants. As shown in the survey data of migrant workers in 2014, migrant workers average per capita monthly consumption expenditure is 944 yuan, yet the share of living expenses accounted for its $47.1 \%$ [1]. Due to the uncertainty of income, migrant workers performance a flexible demand for the price of housing and deliberately evade to rent bigger places with better facilities. In other words, lack of enough and effective risk dispersion, migrants are more likely to select a cautious consumption tendency of a low current consumption and a high propensity to save and then to maintain the stability of the housing consumption in the existing conditions.

Employment, which plays a greater role in the choice of housing type, involves not only the different jobs with diversity income, but also with the housing supply mechanism based on different occupations. At the report by National Statistics bureau points out migrants who get free accommodation from the employer or units accounted for $46.8 \%$ of the proportion of total migrant workers [1]. The majority of free collective dormitories are provided by such labor intensive industries as the manufacturing and the construction. While most of the migrants who are employed by the services and the retailing have to access to housing by rent their own. Additionally, the distance between working place and dwellings should be taken into account. That is no doubt that in order to reduce the commuting costs migrants are more willing to live closer to working place under the premise of same conditions.

Several other individual characteristics such as age, gender, marital status and education are important in migrants' housing decisions, especially the intension of staying in city. Temporary migrants intending to return to rural areas of origin after retire, would continue to shift the geographical location of migrant and invest less in accommodations. But over time, they are more likely to invest more in living to improve housing conditions at urban destinations as long as urban ties surpass rural ties, becoming the permanent migrants.

Based on residential segregation theory, a large of migrants prefers to live in a compact community, which is driven by the social culture homogeneity. Because living close to fellow migrants, who come from the same original village or engage in the same occupation and have the similar financial capacity and background of life experience, can provide a sense of community and mental support especially be helpful for migrants whose accents make it difficult to communicate with the local and who feel that the locals often look down on them.

\subsection{Macro Level: Institution Factors}

Migrants, who migrant through temporary movement without official changes of household registration from the origin to the destination and be expected to eventually return to their home places after retire, have restricted access to housing in comparison with the locals. 
Migrants are largely excluded from the mainstream housing distribution and supply system, with the linkage between household registration and urban housing being largely intact, which has resulted in the overall crowding and mediocre conditions of migrant housing in urban China. For instance, the Economic and Comfortable Housings are reserved for urban residents only. Meanwhile, from the perspective of commercial housing supply in the first housing market, for real estate developers, their goal is to pursuit the profit maximization. As a result, they prefer for the high-end market and not take the relatively deprived floating population as the target market to exploit housing market. In second housing market, the filtered accommodations are the main housing source of low incomes (e.g. the migrants) even homeless [14]. Because the quality of high-income resident's accommodation will get aging and then will be depreciated. For pursuing better accommodations, high incomes waive their existing houses. As a result, the obsolete houses will enter into the lower lever consumer market and the low incomes could be benefited under a relatively low price. But, even in second housing market, if migrants want to loan housing, they must to face some resistance to get bank loans. Because migrants lack of housing provident fund system and collateral, the probability of success to get bank loans are slim. Renting the self-constructed housing in suburban areas is a compromise solution for migrant. Unfortunately, the rental market is still immature, with thousands of intermediate rental agencies operating and regulations taking effect only recently.

According to the social exclusion theory, the multiple restricted dilemmas of access to migrant housing in urban China maintain strong linkage with the institution factor-household registration system. The existence of social exclusion leads the migrants have a limited possibility to own private house or get public rental house than the natives.

\section{Suggestions to Improve the Conditions of Migrant Housing}

Several concrete measures should be implemented to improve the housing conditions for migrant workers in urban China. Firstly, to speed up the pace of reform of the land system and household registration system remove the restriction from institution factors and then reduce the cost of migrant workers smoothly settle in the city. For example, we can implement the policy of covering part of price in the homestead to improve the efficiency of rural land transfer. Secondly, establishment of the perfect alternative multi-level housing security systems to help migrants to obtain accommodations more easily in urban China: build moderate low-rent housing, improve the assigned process of public rental housing, remove restrictions on economic and comfortable housing for migrants who without urban authorities, give a housing benefit supplement to help low-income migrants acquire commercial housing through market mechanisms. Thirdly, establishment of housing provident fund system for the city's floating population enhance their purchasing ability to pay commercial housing in market. Finally, to promote the planning and construction of some affordable housing like low-cost housing and economic and comfortable housing for migrants in the mixed areas close to local residents, which is beneficial to blend the migrants into the local culture and social connections.

\section{Conclusion}

Farmers, as the surplus labor in rural area, have been migrating to cities since the reforming and opening-up, highly promoted the process of urbanization. However, the housing problem is one of the important factors and bases affecting migration and urbanization of migrants. To settle down the migrants, housing problem has thus become a central topic among scholars. This paper reviews the present situation of migrant housing in urban China, from four aspects such as the housing choice, spatial distribution of residence, housing condition and housing satisfactory, and also analyzes the influencing factors leading to the constrains based on the theory of residential segregation and social exclusion. The research explores that rental housing is a particularly compromise solution for migrants settling in suburban areas in both cities in urban China, with a variety of housing types being involved such as collective dormitory, self-constructed housing, and self-purchased house. The residential choice of migrants in space distribution takes place in two types: through living in a compact community and through living in small and dispersed groups. Given the overall inadequate housing conditions, however, migrants express less dissatisfaction with their current housing situations. The country's unique institutional factors, particularly the existing household registration system linkage with the temporary status for migrants, together with the individual characteristics, contribute to this multiple constrains. In order to deal with this problem, to speed up the pace of reform of the land and household registration system, to establish the perfect alternative multi-level housing security system and housing provident fund system, and to promote the planning 
and construction of some affordable housing like low-cost housing and economic and comfortable housing for migrants are the effective measures to improve the living standard of migrant housing.

\section{Fund Project}

Natural Science Foundation of Guangdong Province, China (Grant No.2014A030310499).

\section{References}

[1] The People's Republic of China National Bureau of Statistics (2014) The Report of the National Survey on Migrant Workers in 2014. http://www.stats.gov.cn/tjsj/zxfb/201504/t20150429_797821.html

[2] Schelling, T.C. (1971) Dynamic Models of Segregation. Journal of Mathematical Sociology, 1, 143-186. http://dx.doi.org/10.1080/0022250X.1971.9989794

[3] Denton, N.A. and Massey, D.S. (1988) Residential Segregation of Black, Hispanics, and Asians by Socioeconomic Status and Generation. Social Science Quarterly, 69, 797-817.

[4] Preston, V., Murdie, R. and Murnaghan, A.M. (2007) The Housing Situation and Needs of Recent Immigrants in the Toronto CMA. CERIS Working Paper, No. 56.

[5] Hanlon, J. (2011) Unsightly Urban Menaces and the Rescaling of Residential Segregation in the United States. Journal of Urban History, 37, 732-756. http://dx.doi.org/10.1177/0096144211407744

[6] Weigher, J. (1980) Housing: Federal Policies and Programs. American Enterprise Institute, Washington DC.

[7] Chandrasekhar, C.A. (2004) Can New Americans Achieve the American Dream? Promoting Homeownership in Immigrant Communities. Harvard Civil Rights-Civil Liberties Law Review, 39, 169-216.

[8] Danso, R.K. and Grant, M.R. (2000) Access to Housing as an Adaptive Strategy for Immigrant Groups: Africans in Calgary. Canadian Ethnic Studies, 32, 19-43.

[9] Hulchanski, J.D. and Shapcott, M. (2004) Introduction: Finding Room in Canada’s Housing System for All Canadians. In: Hulchanski, D. and Shapcott, M., Eds., Finding Room: Policy Options for a Canadian Rental Housing Strategy, University of Toronto Press, Centre for Urban and Community Studies, Toronto, 3-12.

[10] Battiston, D., Dickens, R., Manning, A. and Wadsworth, J. (2014) Immigration and the Access to Social Housing in the UK. CEP Discussion Paper No. 1264.

[11] Chatterjee, S. and Zahirovic-Herbert, V. (2011) Homeownership and Housing Equity: An Examination of NativeImmigrant Differences in Housing Wealth. International Advances in Economic Research, 17, 211-223. http://dx.doi.org/10.1007/s11294-011-9294-3

[12] Yang, S.M. and Wang, H.S. (2008) The Change of Xinjiang Village in Beijing-One of the Investigation of Xinjiang Village in Beijing. Northwest Ethnic Studies, 2.

[13] Chen, H.B. and Xu, Z.Z. (2013) Problems and Countermeasures of Housing for Migrant Workers—Taking Zhengzhou City as an Example. Regional Research and Development, 1, 41-44.

[14] O’Flaherty, B. (1995) An Economic Theory of Homelessness and Housing. Journal of Housing Economics, 4, 13-49. http://dx.doi.org/10.1006/jhec.1995.1002 